\title{
NOTAS PRELIMINARES SOBRE O TERRAPLANISMO E O COVID-19*
}

Carlos Lucena

Lurdes Lucena

\section{Introdução}

O "Show de Truman" dirigido por Peter Weir lançado em 1998 pela Paramount Pictures retrata a vida de um corretor de seguros Truman Burbank - brilhantemente interpretado por Jim Carrey. O filme tem início a partir do episódio número 10.909 quando do trigésimo aniversário do personagem em questão. Em um universo controlado, o corretor é acompanhado por milhares de câmeras de televisão que transmitem o cotidiano de sua vida ao vivo para todo o mundo desde o seu nascimento.

A sua convivência social é marcada pelas relações familiares, vizinhos e amigos em um universo repetitivo que se apresenta nos trinta anos de reprodução ininterrupta do programa. O maior estúdio cinematográfico do mundo é utilizado para o desenvolvimento da programação, construído como uma espécie de bolha onde se limitam as relações sociais.

$\mathrm{Na}$ estória, todos os personagens, à exceção de Truman, são atores contratados. Como a transmissão é contínua, as propagandas são feitas no próprio desenrolar da programação. Ali, tudo está à venda, desde produtos de alimentação, tendências da moda, imóveis, entre outros. Truman vive em um mundo fake news. Imagina que controla da sua vida, quando na realidade é uma experiência de laboratório.

O processo de descoberta de sua condição social é comovente. O personagem passa por uma metamorfose processual que redefine

${ }^{*}$ DOI - 10.29388/978-65-86678-07-9-0-f.175-188 
sua percepção sobre o mundo. Seu despertar processual propicia a construção gradativa de um ato de percepção que denuncia a sua própria condição manifestando-o como uma coisa que atende a interesses que não são os seus. A sua reação é a negação dessa condição, o direito de transcender de uma coisa para um ser humano. O diálogo expresso na cena final do filme exemplifica esta afirmação.

\author{
Truman - Quem sou eu? \\ Diretor - $O$ astro \\ Truman - Nada é real \\ Diretor - Vc é real. Não existem mais verdades lá fora do que o mun- \\ do que eu criei para vc. Lá fora tem trapaças, mas no meu mundo vc \\ não tem nada a temer. \\ Diretor - Eu conheço vc desde que nasceu. Vc não pode ir embora. \\ Diz alguma coisa. Vc está na televisão, ao vivo, para o mundo intei- \\ ro. \\ Truman - Se por acaso não nos vimos, bom dia, boa tarde, boa noite, \\ risos \\ E se despede aos olhos de milhares de telespectadores.
}

O cenário de ficção apresentado no filme "O Show de Truman" retrata o complexo processo social presente na sociedade. As falas dos personagens exemplificadas entre o "nada é real" e o "vc é real" apresentam formas de interpretação movidas por subjetividades distintas que visam construir o mundo a sua própria imagem. Esses elementos têm como pressuposto a negação da realidade como ela o é, construindo um mundo imaginativo como pretensão do real. Tendo como referência que a imaginação é facultativa à subjetividade individual, seus desdobramentos e percepções dispensam qualquer afirmação científica. Em outras palavras, a imaginação e as emoções se apresentam como o real simplesmente por que se imagina que elas sejam.

A percepção das fantasias como expressão da realidade expressam uma espécie de idealismo vulgar que não teorizaremos nestas notas preliminares. Talvez possa ser exagerado estabelecer qualquer com- 
paração à história do idealismo no pensamento filosófico, pois a amplitude das análises carece de qualquer comparação infundada. O que se vê, isso sim, é a tentativa, não tão nova assim, de estabelecer materialidade ao universo da ficção, das emoções e dos ressentimentos.

\section{Alguns pressupostos do Terraplanismo}

As indagações sobre o formato da Terra não são tão novos assim. Os povos babilônicos assentados na ideia cultural da existência de um submundo sobrenatural afirmavam que a terra era oca. Já os egípcios a entendiam como sendo quadrada.

Figura 1- Cosmogonia Egípcia

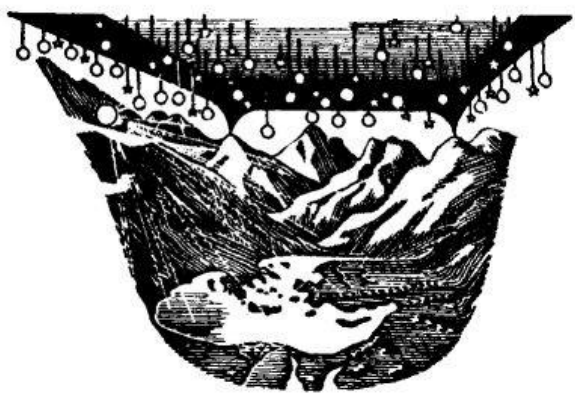

Fonte: https://www.lockhaven.edu/ dsimanek/flat/flateart.htm

O terraplanismo se sustenta a partir dos seguintes elementos: a Antártida é uma parede de gelo que represa a água dos mares e oceanos. O horizonte é atua como uma neblina que limita a visão dos seres humanos. A gravidade é uma ilusão. Existe isso sim uma força desconhecida na ordem de $9,8 \mathrm{~m} / \mathrm{s}^{2}$ que prende todos os sólidos no chão. A Lua está a $5 \mathrm{mil} \mathrm{km} \mathrm{da} \mathrm{Terra} \mathrm{e} \mathrm{seu} \mathrm{raio} \mathrm{é} \mathrm{de} 51,5 \mathrm{~km}$. O Sol possui tamanho e distância similar à da Lua. Ele possui órbitas diferentes que garantem a existência do dia e da noite, e as diferentes estações do ano. $\mathrm{O}$ centro da terra plana é o Polo Norte. O seu interior magnetizado mantém a órbita do Sol e da Lua em torno da Terra e atrai os ponteiros das bússolas. O planeta Terra é separado do universo por um 
domo. As estrelas são fontes luminosas que existem próximas à Terra. O equador é mais quente por estar abaixo do Sol.

Estas afirmações se sustentam a partir das reflexões de um conjunto de autores aos quais elucidamos a seguir. Em 1881, Samuel Rowbotham publicou o livro "Zetetic Astronomiy: Earth not a globe", ao qual afirmou que o sol não era um astro gigante, mas uma pequena estrela de fogo próxima à terra.

\begin{abstract}
"Um homem de fé não pode deixar de ver, e não demorará a admitir, que todas as teorias nas quais filósofos aventureiros mergulham, não são nem um pouco melhores do que areias movediças traiçoeiras, nas quais muitos dos mais profundos pensadores têm sido engolidos e provavelmente se perdido completamente. Através desse processo mental de concatenação muitas mentes altamente inteligentes têm sido levadas a renunciar e desertar dos rankings do ateísmo e filosofia especulativa, e se juntar a lista do exército de devotos cristãos. Muitos têm se alegrado, quase além da conta, porque a questão do verdadeiro formato e posição da terra lhes foi apresentado novamente, e, sem sombra de dúvidas, muitos ainda serão conduzidos novamente à plenitude dessa verdade." Samuel B. Rowbotham² .
\end{abstract}

Wilbur Glenn Voliva (1870-1942) em concordância com Rowbotham, apontou que o sol possuía no máximo 32 milhas de diâmetro e sua distância não ultrapassava 3.000 milhas do planeta Terra. Centrado em fundamentos teológicos, afirmou que o sol foi uma criação de Deus para aquecer e iluminar a Terra, não fazendo qualquer sentido estar distante do planeta ${ }^{3}$.

\footnotetext{
${ }^{1}$ Samuel Rowbotham. Zetetic Astronomiy: Earth not a globe. Simpkin, Marshall, and CO, 1881.

${ }^{2}$ Fonte: https://clubedeautores.com.br/livro/astronomia-zetetica

${ }^{3}$ Fonte: <https://wiki.tfes.org/Wilbur_Glenn_Voliva. $>$
} 
Figura 1 - Mapa da Terra Plana de Voliva

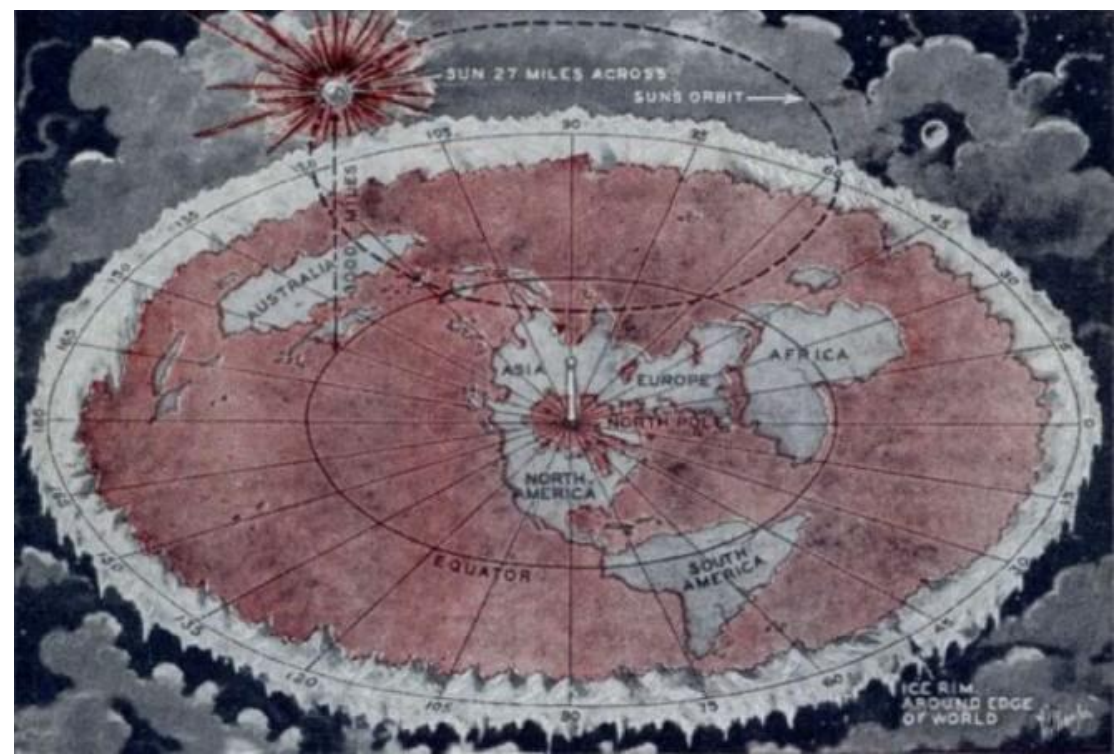

Fonte: https://www.lockhaven.edu/ dsimanek/flat/flateart.htm

A astronomia era alvo de severas críticas, sendo os astrônomos entendidos como ignorantes.

Embora seja verdade que a evolução matou milhares, é igualmente verdade que a astronomia moderna matou dezenas de milhares! Multidões de cristãos até então professos, incapazes de conciliar as teorias da Astronomia Moderna com as claras declarações da Bíblia, aceitaram essas teorias e rejeitaram a Bíblia, para que se possa dizer com sinceridade que a fé de milhões em Deus, em Jesus Cristo, e na Bíblia como a Palavra Inspirada de Deus, foi arrancada e completamente destruída. [...] A astronomia moderna, a evolução e as críticas mais altas são uma trindade de males - a astronomia moderna não é de modo algum o menor dos três - que são doutrinas de se dução de demônios, originadas e ensinadas com o objetivo de destruir, nas mentes, corações e vidas do povo, sua aceitação da Bíblia 
como a Palavra Inspirada de Deus e sua crença e prática na religião cristã ${ }^{4}$.

A afirmação de a Terra ser plana se justificava em um entendimento teológico sobre o formato do planeta.

Os chamados fundamentalistas das igrejas, em oposição ao modernismo, esticam o mosquito da evolução e engolem o camelo da astronomia moderna. Todos os principais modernistas declaram que a Bíblia ensina que a Terra é um plano estacionário. Nessa declaração, eles estão certos, apesar de rejeitarem a Bíblia e aceitarem os ensinamentos da Astronomia Moderna. Os fundamentalistas que professam acreditar que a Bíblia é a Palavra de Deus inspirada e que, diante dessa profissão, aceitam as teorias astronômicas que são ensinadas nas escolas, mentem sua profissão [...] A Bíblia ensina claramente que a terra é um plano. A astronomia moderna ensina que a terra é um globo. Ambos não podem ser verdadeiros. Uma das duas posições deve ser falsa. Qual você, como cristão professo, aceitará - o ensino claro da Bíblia, a Palavra inspirada de Deus ou as especulações selvagens e contidas dos astrônomos infiéis?

Em 1966, Samuel Shenton (1903-1971) ${ }^{5}$ publicou um panfleto intitulado "Plano da Verdade". Sua afirmação foi que a corrida espacial e a astronomia moderna eram uma ofensa Deus, cuja arrogância da humanidade seria passível de punição no futuro ${ }^{6}$.

\footnotetext{
${ }^{4}$ Fonte: < $\underline{\text { https://www.cantab.net/users/michael.behrend/ebooks/PlaneTruth/pages/ }}$ Chapter 08.html>

${ }^{5}$ Samuel Shenton conseguiu conquistar muitos seguidores e permaneceu o presidente da sociedade até sua morte em 1971. Quando as primeiras fotografias da Terra foram publicadas nos primeiros anos dos voos espaciais, Shenton as descartou como uma ilusão de ótica causada por uma ampla lentes de ângulo que faziam a Terra parecer curva quando não estava. Mais tarde, ele descartaria todas as fotos como falsas, juntamente com todo o programa espacial.

Fonte: https://www.lockhaven.edu/ dsimanek/flat/flateart.htm

6 Donald E. Simanek. A Terra Plana. Disponível em: https://www.lockhaven.edu/ dsimanek/flat/flateart.htm
} 


\title{
Figura 2 - Brochura da Sociedade da Terra Plana
}

\section{THE FLAT EARTH SOGIETY}

\author{
President : \\ W. Mills, \\ 7 Vale Grove, \\ Finsbury Park, N.4. \\ Organizing Secretary : \\ S. SHENron, \\ 22 London Road, \\ Dover.
}

The International Flat Earth Society has been established to prove by sound reasoning and factual evidence that the present accepted theory, that the Earth is a globe spinning on its axis every 24 hours and at the same time describing an orbit round the Sun at a speed of 66,000 m.p.h., is contrary to all experience and to sound commonsense.

In ancient times the Earth was regarded as plane, and this is expressed in all literature up to a few hundreds of years ago. The theory has fallen into disfavour, owing mainly to the dogmatism of modern science and popular education in schools, which leads to prejudice in favour of the globular theory from the start.

It is always a pity to allow false theories to pass unchallenged, and it is hoped that the Flat Earth Socicty will do much to undo the harm that has been caused. Remember that the truth of the plane figure of the Earth can be shown by irrefutable evidence, and anyone who is interested in becoming a member is asked to contact the President or the Organising Secretaryl In future, it is hoped to hold regular meetings of the Society.

DECEMBER 20TH, 1956 .

Fonte: https://www.lockhaven.edu/ dsimanek/flat/flateart.htm

A Sociedade Internacional da Terra Plana foi estabelecida para provar, com um bom raciocínio e evidências factuais, que o presente aceita a teoria de que a Terra é um globo girando em seu eixo a cada 24 horas e, ao mesmo tempo, descrevendo uma órbita ao redor do Sol a uma velocidade de $66.000 \mathrm{mph}$, é contrário a toda experiência e parece bom senso.

Nos tempos antigos, o Earh era considerado plano, e isso é expresso em toda a literatura até algumas centenas de anos atrás. A teoria caiu em desagrado, devido principalmente ao dogmatismo da ciência moderna e da educação popular nas es- 
colas, o que leva ao preconceito a favor da teoria globular desde o início.

É sempre uma pena permitir que falsas teorias passem incontestadas, e espera-se que a Sociedade da Terra Plana faça muito para desfazer os danos causados. Lembre-se de que a verdade da figura plana da Terra pode ser demonstrada por evidências irrefutáveis, e qualquer pessoa interessada em se tornar membro deve entrar em contato com o Presidente ou o Secretário Organizador. No futuro, espera-se realizar reuniões regulares da Sociedade.

20 de dezembro ${ }^{\text {th }}$ de 1956.

Charles K. Johnson (1924-2001) foi presidente da Sociedade Internacional de Terra Plana afirmou que a ideia da terra redonda consistia em uma conspiração para iludir a humanidade. As viagens à órbita da terra e ao espaço eram farsas, visto que em seu entendimento, era impossível orbitar a Terra. Os programas espaciais tinham como objetivo sustentar o que denominava como "mito moribundo", ou seja, a afirmação da Terra ser redonda. Seus argumentos são de cunho teológico e sem qualquer base de sustentação científica. Atenta-se a versículos tanto do Antigo como do Novo Testamento. "Ele baseou suas próprias ideias nas referências do Antigo Testamento a uma terra plana e no Novo Testamento dizendo que Jesus subiu ao céu. 'Se a Terra girasse uma bola no espaço, não haveria para cima ou para baixo"', disse ele à revista Newsweek em 19847.

A tentativa da teoria copernicana de refutar a existência de Jesus é utilizada como justificativa para suas afirmações. Entendia que apenas os crentes na Bíblia concebem a Terra como plana. Os cientistas eram entendidos como feiticeiros responsáveis por construir uma farsa generalizada para eleger a supremacia da ciência em detrimento da religião.

\footnotetext{
${ }^{7}$ Fonte: https://www.nytimes.com/2001/03/25/us/charles-johnson-76-proponent-offlat-earth.html
} 
Afirmamos que o que hoje é chamado de 'Ciência' e 'cientistas' consiste na mesma velha gangue de feiticeiros, feiticeiros, contadores de histórias, os 'Sacerdotes-Entertainers' para as pessoas comuns. "Ciência" consiste em uma mistura oculta e esquisita da teologia da teoria da bobagem não relacionada ao mundo real de fatos, tecnologia e invenções, edifícios altos e carros velozes, aviões e outras coisas reais e boas da vida; a tecnologia não tem nenhuma relação com a teia da teoria científica idiota. Todos os inventores foram anti-ciência. Os irmãos Wright disseram: "A teoria da ciência nos sustentou por anos. Quando jogamos fora toda a ciência, partindo de experimentos e experiências, inventamos o avião". [...] A ciência 'prova' a terra de uma 'bola' com palavras de 'escritura'. PROVAMOS a Terra plana por experiência, demonstrado e demonstrável. A Terra Plana é um Fato, não uma "teoria"! A ciência é uma religião falsa, o ópio das massas. Eu mesmo considero isso como um começo de Sanidade confessar 'a criação prova que havia um Criador' e que existe um Deus ou Criador [...] Existe. [...] O fato de a Terra ser plana não é minha opinião, é um fato comprovado. Não há razão terrena para que um membro íntegro e honesto dos humanos eleitos de elite o assine. Também um fato, hoje a elite da terra vive no mundo plano. Somente o "rebanho" ilógico e irracional prefere a estranha teologia oculta e estranha da velha superstição grega, que transforma uma bola em rotação ${ }^{8}$ !

Eric Dubay ${ }^{9}$ também se assenta na tese conspiratória voltada a doutrinar milhares de seres humanos, seja através de livros, propaganda e universidades. Para ele, a NASA e a Maçonaria são os grandes propagandistas do que denomina como farsa da Terra Redonda. Ao

8 Fonte: <https://www.nytimes.com/2001/03/25/us/charles-johnson-76-proponentof-flat-earth.html $>$

${ }^{9}$ Eric Dubay. 200 Proofs Earth Is Not a Spinning Ball. New York: Createspace Independent Publishing Platform, 2018.

. The Atlantean Conspiracy. New York: Createspace Independent Publishing Platform, 2013

2018

. The Earth Plane. New York: Createspace Independent Publishing Platform

. The flat-earth Conspiracy. New York: Createspace Independent Publishing Platform 2014 
contrário das explicações teológicas apresentadas anteriormente, Dubay, acredita que Jesus Cristo nunca existiu.

\section{A Influência do terraplanismo na interpretação dos efeitos do covid-19}

O terraplanismo não possui nenhuma comprovação científica, sustentada em universo repetitivo de afirmações sobre sua veracidade potencializado pelas redes sociais. Nesse sentido, a negação científica de seus pressupostos colocam a ciência e seus resultados em um universo conspirativo sem qualquer embasamento.

A sensação de não pertencimento das pessoas somada ao elevado índice de estranhamento do trabalho potencializam afirmações que as colocam como sujeitos em um mundo ao qual não o são. Este movimento potencializa análises simplistas em que emergem os novos tolos que regozijam uma pretensa verdade que só existe em sua imaginação. Contudo, a construção destes absurdos transcendem os pressupostos do terraplanismo.

A ausência de bases científicas materializa discursos políticos que visam reinventar a realidade a seus interesses. $\mathrm{O}$ crescimento do populismo de extrema-direita potencializa esta afirmação. Suas afirmações, de início, satirizadas e não levadas a sério, tomaram uma dimensão maior do que se imaginava. O palco estava colocado e o universo de tolos para confirmá-las era maior do que se imaginava, até porque essas idiotices iam de acordo ao que muitos queriam ouvir e acreditar.

A conquista das emoções humanas somadas à negação científica elegem como verdade aquilo que se pretende ser. A estratégia se sustenta em desqualificar todo e qualquer agente que defenda pressupostos diferentes dos seus. O uso de uma linguagem repleta de símbolos e apelo à emoções se apresenta como o interlocutor dos incultos. $\mathrm{O}$ ódio toma um fim em si mesmo, tanto daqueles que o afirmam como os que o negam. 
O prolongamento da crise econômica em âmbito mundial fortalece esta estratégia. De acordo com dados da Organização Mundial da Saúde até o início de agosto tinham 18.614.177 casos de covid-19 e 702.642 mortos no planeta. Os dados mundiais referentes ao covid-19 são alarmantes, tal qual demonstra o quadro a seguir.

Quadro 1 - Número de infectados e mortes pelo covid-19 até o final de julho de 2020 em alguns países do mundo

\begin{tabular}{|c|c|c|}
\hline País & Número de Infectados & Mortes \\
\hline Estados Unidos & 4582742 & 154534 \\
\hline Brasil & 2065281 & 91807 \\
\hline Índia & 1632305 & 35736 \\
\hline Rússia & 839974 & 13971 \\
\hline África do Sul & 482486 & 7737 \\
\hline
\end{tabular}

Fonte: https://dadoscoronavirus.dasa.com.br/

O quadro 1 demonstra que os Estados Unidos e o Brasil apresentam o maior número de casos. No Brasil, a região sudeste e nela o estado de São Paulo são os que possuem o maior número de infectados e mortes, tal qual demonstra os quadros 2 e 3.

Quadro 2 - Número de infectados e mortes pelo covid-19 até 06 de agosto de 2020 no Brasil

\begin{tabular}{|c|c|c|}
\hline Região & Número de Infectados & Mortes \\
\hline Sudeste & 1.004 .105 & 44.360 \\
\hline Nordeste & 922.461 & 30.145 \\
\hline Norte & 434.067 & 12.205 \\
\hline
\end{tabular}




\begin{tabular}{|c|c|c|}
\hline Centro-Oeste & 286.839 & 5.971 \\
\hline Sul & 264.740 & 5.812 \\
\hline
\end{tabular}

Fonte: Painel Coronavirus Brasil - https://covid.saude.gov.br/

Quadro 3 - Número de infectados e mortes pelo covid-19 até o final de julho de 2020 no Brasil

\begin{tabular}{|c|c|c|}
\hline Estado & Número de Infectados & Mortes \\
\hline São Paulo & 540740 & 23102 \\
\hline Ceará & 172594 & 7673 \\
\hline Rio de Janeiro & 163655 & 13363 \\
\hline Bahia & 161355 & 3372 \\
\hline Pará & 153513 & 5694 \\
\hline
\end{tabular}

Fonte: O tempo - https://www.otempo.com.br/coronavirus

O trato com os dados apresentados nos quadros 1 e 2 se justifica pela adoção de princípios do terraplanismo. O negacionismo científico utilizado como estratégia de negar os efeitos do covid-19 toma dimensões similares às interpretações terraplanistas sobre o formato da terra. A ciência, suas pesquisas e resultados são apresentados como Fake News ... e muitos acreditam nisso.

Os povos indígenas correm grande risco no Brasil. De acordo com dados da Articulação de Povos Indígenas no Brasil, em 06 de agosto de 2020 existiam 22656 casos confirmados, 639 mortos e 148 povos afetados pelo covid-19. 


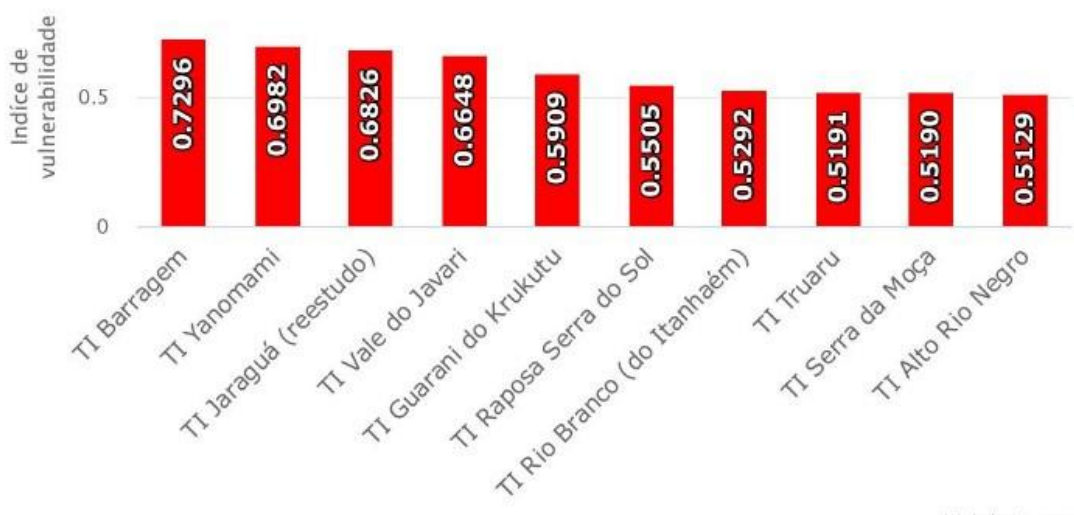

Fonte: Articulação de Povos Indígenas no Brasil

Tendo como referência as necessidades imediatas de parcela considerável da população, tanto os Estados Unidos como o Brasil negaram os impactos do covid-19, tendo como resultado o maior índice de infectados e mortos do planeta.

O apelo ao coronavírus como uma teoria da conspiração que visava desestabilizar o governo federal brasileiro, a constante negação presidencial sobre a importância do isolamento social e o entendimento da pandemia como um fenômeno de menor importância potencializaram o fracasso nacional no enfrentamento do covid-19. As análises fictícias oriundas do terraplanismo foram utilizadas como forma de negar os apelos científicos pelo isolamento social.

O resultado, infelizmente, foi a morte de milhares de seres humanos, cujos desdobramentos finais ainda são inconcebíveis de se prever... 


\section{Referências}

Brochura da Sociedade da Terra Plana. Disponível em: $<\underline{\text { https://www.- }}$ lockhaven.edu/ dsimanek/flat/flateart.htm $>$ Acesso em: 06 ago. 2020

DUBAY Eric. 200 Proofs Earth Is Not a Spinning Ball. New York: Createspace Independent Publishing Platform, 2018.

. The Atlantean Conspiracy. New York: Createspace Independent Publishing Platform, 2013

. The Earth Plane. New York: Createspace Independent Publishing Platform 2018

. The flat-earth Conspiracy. New York: Createspace Independent Publishing Platform 2014

The New York Times. Disponível em: < https://www.nytimes.com/ 2001/03/25/us/charles-johnson-76-proponent-of-flat-earth.html > Acesso em 06 ago. 2020

SIMANEK, Donald E.. A Terra Plana. Disponível em: < $\underline{\text { https://www.- }}$ lockhaven.edu/ dsimanek/flat/flateart.htm $>$ Acesso em 06 ago. 2020

ROWBOTHAM, Samuel. Zetetic Astronomiy: Earth not a globe. Simpkin, Marshall, and CO, 1881. 